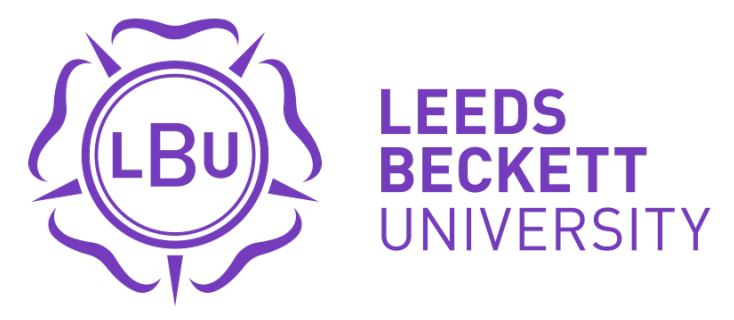

Citation:

Dashper, K and Buchmann, A (2019) Multispecies event experiences : Introducing more-than-human perspectives to event studies. Journal of Policy Research in Tourism, Leisure and Events. ISSN 1940-7963 DOI: https://doi.org/10.1080/19407963.2019.1701791

Link to Leeds Beckett Repository record:

https://eprints.leedsbeckett.ac.uk/id/eprint/6376/

Document Version:

Article (Accepted Version)

This is an Accepted Manuscript of an article published by Taylor \& Francis in Journal of Policy Research in Tourism, Leisure and Events on 11 December 2019, available online: http://www.tandfonline.com/10.1080/19407963.2019.1701791.

The aim of the Leeds Beckett Repository is to provide open access to our research, as required by funder policies and permitted by publishers and copyright law.

The Leeds Beckett repository holds a wide range of publications, each of which has been checked for copyright and the relevant embargo period has been applied by the Research Services team.

We operate on a standard take-down policy. If you are the author or publisher of an output and you would like it removed from the repository, please contact us and we will investigate on a case-by-case basis.

Each thesis in the repository has been cleared where necessary by the author for third party copyright. If you would like a thesis to be removed from the repository or believe there is an issue with copyright, please contact us on openaccess@leedsbeckett.ac.uk and we will investigate on a case-by-case basis. 


\title{
Multispecies event experiences: Introducing more-than-human perspectives to event studies
}

\section{Katherine Dashper $^{1 \mathrm{~A}}$ and Anne Buchmann ${ }^{\mathrm{B}}$}

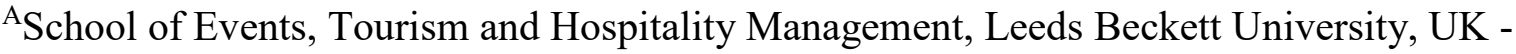
Orcid.org/0000-0002-2415-2290

${ }^{\mathrm{B}}$ Tourism Department, Business School, University of Newcastle, Australia

\section{Accepted for publication in Journal of Policy Research in Tourism, Leisure and Events} 27/11/19

\begin{abstract}
Events are all about experiences, and event managers and designers are encouraged to explore innovative and creative ways to engage and excite customers, creating satisfaction and loyalty. These experiences are not always solely human phenomena, although event studies as an academic field has yet to acknowledge this multispecies aspect and remains firmly anthropocentric. In this paper we introduce more-than-human perspectives to event studies to illustrate how moving beyond humanist paradigms can open up alternative insights and add to the richness of understanding about event experiences. Drawing on ethnographic fieldwork conducted at equestrian 'endurance riding' events both in the UK and Australia, we apply a multispecies lens to the investigation of event experiences. In equestrian events, the experiences of human participants are profoundly shaped by those of the equine participants, and the interactions between the two. Endurance riding offers an interesting example of one
\end{abstract}

\footnotetext{
${ }^{1}$ Corresponding author Katherine Dashper, k.dashper@leedsbeckett.ac.uk
} 
'contact zone' between human and nonhuman, as horse and human work together to create sporting performance, travelling through varied landscapes and environments. In such ways, horses are co-creaters of event experiences, actively shaping and helping create those encounters, whether they be memorable or mundane. By decentring human experience, morethan-human perspectives open up possibilities for exploring and understanding the richness of event experiences that involve multiple actors and species.

Keywords: endurance riding; equestrian; ethnography; events; experiences; multispecies 


\section{Introduction}

It is over 20 years since Pine and Gilmore (1998) heralded the emergence of the experience economy as 'the next competitive battleground' (p.98) for businesses. In the intervening period researchers and practitioners have grappled with the implications of this paradigm shift, in terms of trying to transcend customer expectations, understand what customers really want from a product, service or company, and trying to design, deliver and measure the elusive notion of 'experience quality' (Chang \& Horng, 2010; Maklan \& Klaus, 2011; Pine \& Gilmore, 2000). This is a response to today's consumer demanding quality services, but also preferring 'those services delivered as part of an overall, packaged experience' (Bladen, Kennell, Abson \& Wilde, 2018, p. 52). There is a tendency towards 'festivalisation' (Carmago, 2007) and events are seen as particularly valuable ways of engaging customers with products and brands.

Consequently, much attention has been paid to how events can be designed and 'choreographed similar to a theatrical production' (Funk, 2017, p. 150) to maximise engagement and communication of brand-related messages (Wood \& Masterman, 2008). Building on insights from marketing (and particularly the subfield of experiential marketing), and drawing largely on methods and perspectives taken from social psychology, the burgeoning literature on event experiences encourages event managers and designers to explore innovative and creative ways to engage and excite customers, creating satisfaction and, hopefully, loyalty (Morgan, 2006, 2008). Whilst this is undoubtedly important, and all events need to be financially viable to continue to run, we argue that this narrow focus misses some of the important aspects of understanding the role of 'experiences' in events, which are about more than just customer satisfaction and brand loyalty, and also encompass deeper 
social and cultural meanings related to identity and belonging, subjects receiving increasing attention in the broader field of event studies (Bennett \& Woodward, 2016).

While some participants engage with specific events through a sense of loyalty to the event brand or product, such as Ironman triathlon events, and iconic equestrian events like the U.S. Tevis Cup or Australia's Quilty, for many event participants - whether as spectators, participants in an activity, volunteers, staff or even many organisers - their involvement with the event may have less to do with brand loyalty than their own personal engagement with the event theme, content, locality or other participants. This may be particularly true of smallscale leisure and community events, which offer a communal space and time for collective experiences built on shared values and interests (Ziakas \& Costa, 2010). People may get involved with an event because it means something to them, and because others in their network are involved. Focus to date has been on understanding event experiences as 'a personal occurrence with emotional significance' (Wood \& Masterman, 2008, p. 4), yet experiences are not just individual phenomena but also include others, whether as companions, service providers, performers or in a variety of other roles. Therefore, research on event experiences needs to move beyond focus on individual responses and reflections on personal experiences, and to try and account for the social and collective aspects of those experiences.

We propose taking this insight a step further and suggest that we need to recognise that those collective experiences often involve not just other people, but also other species. Event research, as with most other areas in the social sciences, is strongly anthropocentric, and sees events as solely human domains; designed, managed and experienced by and for humans alone. Yet nonhumans often play important roles in events, whether as a canine companion at 
a country fair, a horse participating in a sports event, a sniffer dog assisting with event security, a cat in a breeding show, or even as food or providers of other products and services to human event attendees (Dashper \& Brymer, 2019; Hickey et al., 2012; Stone, 2019). Viewing events as solely human phenomena and considering experiences only in relation to people and human-human encounters misses the important roles that many nonhuman animals play in co-creating memorable event experiences.

In this paper we introduce a more-than-human perspective to the study of event experience to argue that moving beyond humanist paradigms opens up new avenues for designing, delivering, understanding and living event experiences. Posthumanist frameworks challenge researchers to refocus attention to view human experiences as but one part of a complex multispecies world. Drawing on ethnographic fieldwork conducted at equestrian events in the UK and Australia, we illustrate how attention to interspecies interactions - in this case between humans and horses - can help draw attention to aspects of event experiences that otherwise may be misunderstood or even go completely unnoticed.

\section{More-than-human perspectives on event experiences}

\section{Introducing more-than-human perspectives}

Most social science research, including that related to event studies, is rooted in implicit humanist assumptions that position humans as the sole legitimate focus for study and consider only human experiences, perspectives and priorities. This gives only a partial view, as 'we live in not just exclusively human societies but in common worlds with other species' (Pacini-Ketchabaw et al., 2016, p. 151), and those other species intermingle with, affect and 
help shape human experiences. Multispecies perspectives attempt to challenge the deeprooted human exceptionalism that positions humans as the only worthy focus for attention, and to acknowledge the importance of nonhuman animals in their own right, and in their interactions with and influences on human worlds. More-than-human perspectives argue that 'what we ontologically understand as 'human' is really a complex relation with other species' (Lloro-Bidart, 2017, p. 113), and so we need to take account of other species in research and practice.

Events research as an academic field of study is still relatively emergent, and so it is perhaps not surprising that the field has yet to engage with multispecies perspectives. However, as our discussion below illustrates, a multispecies lens offers a fruitful approach for understanding some of the complexities of event experiences. Berridge (2012, p. 274) argues that '[m]odern event management is largely about delivery of experiences', and we suggest that by recognising that those experiences are not solely human phenomena, and that nonhuman animals can and do play important roles in event spaces, researchers can explore different aspects of event experiences leading to alternative insights and adding to the richness of understanding.

\section{Event experiences}

Event experiences are multifaceted, complex and dynamic, changing over the course of a single event, and affected by a range of factors within and beyond the control of event managers (Madrigal, 2003; Pettersson \& Getz, 2009). To try and understand some of the complexity of event experiences on different levels and from different positions, a variety of approaches may be necessary. Kruger and Saayman (2012) identify four critical success factors for creating memorable experiences at events: amenities; marketing; personnel and 
provisions; and, comfort and visibility. This provides useful information to both researchers and event managers and offers advice about the basic requirements for delivering enjoyable event experiences. The notion of 'eventscape' is also useful here, describing 'the spatially dispersed nature of an event and the way the landscape represents an environmental resource and a series of inter-related places that are temporarily transformed by the event' (Brown, Lee, King \& Shipway, 2015, p. 511), further enhacing the overall event experience. Such eventscapes inform the 'experienscape' formed by a 'combination of the tangible elements which shape the event environment and therefore influence the emotional responses and experiences of attendees, event staff and other involved stakeholders' (Tattersall \& Cooper, 2014, p. 142). These perspectives offer interesting insights, but the specific experiences of event participants may disappear from focus. Wood and Moss (2015) use Descriptive Experience Sampling (DES) to try to access the inner meanings and emotional responses of event attendees through their research at live music events. This approach focuses on the individual, and their internalised feelings and perceptions, but pays little attention to the social context of event experiences. Helgadóttir and Dashper (2016) focus more on the social construction of event experiences and the importance of shared understandings for creating meaning and feelings of belonging and the sense of being an insider or outsider at a sporting event. However, although their research took place at an explicitly multispecies event $-\mathrm{a}$ horse festival in Iceland - they focus solely on the human participants and do not consider the multispecies aspects of those event experiences.

The concept of 'experience' is broad and deep, and it is unlikely that one approach can capture all its complexities. All of the studies discussed above contribute to understanding of the elusive nature of event experiences, yet all also have some shortcomings and leave many aspects of 'experience' unexplored. A multispecies perspective can add to this expanding 
field, by offering another position from which to try to understand event experiences.

Through decentring human experience, and acknowledging the importance and agency of nonhuman animals in event spaces, a multispecies perspective opens up different questions about what makes a 'good' or memorable event experience, and what those experiences can mean to the human participants.

\section{Research approach and methods}

Any attempt to research 'experiences' comes up against methodological challenges: how can we access others' inner experiences (Hulburt \& Havey, 2001)? This becomes even more complex when those others include nonhuman animals as well as people: how can we 'know' what an animal of another species feels or experiences? The difficulty implied in these questions is perhaps one reason for the continued anthropocentrism in social science research as it is problematic to claim to 'know' an other, particularly one of another species. Still, as Clarke and Knights (2018, p. 5) argue, 'our inability to directly access the inner worlds of nonhuman animals is not an excuse for erasing their voice.' Consequently, in any research informed by multispecies perspectives there must be an attempt, at least to some extent, to account for the experiences of nonhuman animals. Therefore, throughout this study we tried to remain alert and sensitive to nonhuman animals' (horses) experiences, as we discuss further below.

The research on experiences in general, including that on event experiences, has been largely dominated by positivist, quantitative approaches, although some studies have employed qualitative methods ranging from interviews to observations (Bouchet et al., 2011; Helgadóttir \& Dashper, 2016; Wood \& Moss, 2015). A number of researchers have argued 
for increased use of ethnographic methods in events research, as a way of trying to understand 'the rich and complex meanings and motivations linked to event experiences' (Jaimangal-Jones, 2014, p. 40; also see Coghlan \& Filo, 2013, Holloway et al., 2010). Ethnographic approaches, involving a variety of data collection methods over a period of time (which may include pre, during and post-event), may begin to overcome some of the challenges of relying on post-event recollections of experiences, or of focusing too much on the individual aspects of emotion to the detriment of the social and collective nature of event experiences (Wood, 2015; Wood \& Kenyon, 2018).

Within more-than-human frameworks, the subpractice of multispecies ethnography has emerged as 'a mode of attunement to the power of nonhuman subjects to shape the world' (Ogden et al., 2013, p. 16-7). Multispecies ethnography attempts to decentre humans, and position our human experiences as but one part of a messy entanglement with a variety of human and nonhuman others, studying the 'contact zones' between nature and culture, and trying to understand interspecies encounters and practices (Haraway, 2008; Kirksey \& Helmreich, 2010). Although multispecies ethnography has limitations in terms of trying to understand nonhuman animals on their own terms, and is beset by issues related to representation, power and voice, it represents a serious attempt to recognise that 'animals are an integral part of an expanded posthuman vision of sociality' (Madden, 2014, p. 285).

Our project is based within the interspecies relationship framework that sees human nature as born of interactions across different forms of life. Thus, as explained above, the study of humans alone is not fruitful; instead we focus on studying 'contact zones' that link the lived experiences of human and nonhuman animals. These moments of encounter are 'full of the complexities of different kinds of unequal power' (Haraway, 2008, p. 218), that are crucial to 
understanding interspecies relationships. Our study focused on the competive equestrian discipline of endurance riding, as a multispecies event. Endurance riding offers an interesting example of one multispecies contact zone, as horse and human work together to create sporting performance, travelling through varied landscapes and environments.

Endurance riding is a specialised form of leisure and competitive riding that involves horserider combinations navigating routes of varied terrain over distances up to $160 \mathrm{~km}$. In addition to completing the route, and being timed doing so, horses are subject to several veterinary checks along the way. Consequently, endurance riding requires partnership between horse and rider, fitness of both, and navigation of different physical environments. Endurance riding offers a relevant context in which to consider human-animal relationships and their interactions with place, space and environment as the horse-rider combination have to work together to travel long distances over varied terrain. The theorectial and methodological approach we adopted in this study is innovative within the events and tourism field, and helps focus attention on how human and nonhuman actors (horses, environment, weather etc.) mutually constitute physically active event experiences.

This study is exploratory in nature, based on primary data obtained from four endurance riding events in the UK and four in Australia in 2018. Informed by the practice of multispecies ethnography, the research design needed to be flexible and open to change, dependent on local situations and contexts. Qualitative methods were required, including in situ interviews, observations and analysis of relevant endurance-related texts. Both authors attended one endurance event in the UK together to observe, discuss and develop a shared practice. The first author attended a further three events in the UK, while the second author attended four in Australia, with our research practices based around the shared protocol. Observations formed an important data source and provide insight into the generalised 
setting, the organisation of the event, and interactions between humans, horses and space. We observed the ebb and flow of the event from the main event site (where horses and people camped and prepared for competition; the race starts and finishes; and important pratices like vet checking occur), observing actions and behaviour of humans and horses, and engaging in informal conversations with a variety of people including riders, grooms, vets, stewards, officials and support crew.

We also conducted targeted interviews with people on site to gain a range of viewpoints based aroud a pre-developed interview guide (to enable comparison between the different national contexts and events), covering a variety of subjects, including: experiences of endurance riding; experiences at the specific event; relationships between people; and, relationships and interactions between people and horses. In total we conducted 55 on-site interviews, with conversations lasting between 20 and 90 minutes. These interviews took place around the event site, for example by horseboxes, at crewing stations and the vet check area, and were not audio recorded, due to the challenges of the outdoor multispecies environment. Instead we wrote notes during and after the interview. In addition, we conducted four longer interviews with endurance officials (which were recorded and transcribed) to gain some background understanding of the sport structure and event requirements, to inform our observations and subsequent analysis.

As this was multispecies ethnography, our observations took in human and equine actions and behaviours, and we tried to remain attuned to the experiences of the horses at the events. We drew on the work of known scholars in the fields of equine studies and equestrian science to offer additional insight on horses' perspectives. Horses are highly socially skilled animals (McLean \& McLean 2008), who develop complex relationships with human individuals 
(Podhajsky, 1970); yet, interspecies communication remains challenging and overall relationships uneven (Nevzorov, 2011). Horses share similar emotions and expressions to humans, and in-fact can interact accordingly. Smith et al.'s (2016) research shows that horses have the ability to read emotions across the species barrier. We have known for a long time that horses are a socially sophisticated species but this is the 'first evidence of horses' abilities to spontaneously discriminate, both behaviourally and physiologically, between positive and negative human facial expressions' (Smith et al., 2016, p. 4). Consequently, although we exercise caution in claiming to 'speak for' the horses in this study we do not agree that just because horses cannot talk they cannot communicate with us and so should not be included in events research. As experienced horsepeople with over 30 years' experience of riding and interaction with horses, as well as some educational and work-related experience in relation to equestrianism and equine science, we were both able to draw on this training to support our social science perspectives in order to try to understand some of the complexities of multispecies interactions and experiences in the context of endurance riding events.

As with any ethnographic project, this resulted in a body of rich data of fieldnotes, interview transcripts and notes, and interspecies observations. All of these forms of written data were analysed using NVivo version 12. Data were thematically coded, based around the issues discussed above, and drawing on insights from both event studies and equine studies. Both researchers coded the data separately and then combined their analysis and discussed areas of divergence in theming and analysis. For this paper we focused on interspecies encounters in the event space and the performance of interspecies relationships. 


\section{Findings}

In trying to account for some of the multispecies experiences that occurred at the equestrian events in this study, we have separated our findings into two sections: multispecies event sites; and, multispecies connections, camaraderie and meaning.

\section{Multispecies event sites}

Many researchers stress the importance of hedonistic aspects of events to producing memorable experiences (Berridge, 2012; Brown, Lee, King \& Shipway, 2015; Morgan, 2008), but the fundamental issues of site design and amenities remain important underpinning concerns and can cause dissatisfaction if not considered adequate by attendees (Kryger \& Saymen, 2012; Morgan, 2006). When an event involves multiple species as active participants this has implications in terms of site design, safety and use. Horses are large and at times unpredictable animals (McGreevy \& McLean, 2010), and so any event that involves large numbers of horses needs to take special account of how the interactions between humans and horses take place in ways to ensure safety, comfort and ease for human and equine participants. Riding is a so-called risk activity, and event organisers need to be prepared for accidents to either horse and/or rider, which could involve serious injury. Preparedness for, and response to, accidents therefore constitute an important aspect of multispecies event experiences and association guidelines specifiy this is an important aspect of equestrian event planning.

Our study encompassed a variety of endurance events in Australia and UK of varying size and level (in terms of competition, and also organisation), and each event involved over 60 horses and more than 100 humans in a field, with very little supporting infrastructure. For example, the typical infrastructure is limited to a green field with a perimeter fence, in which 
the towing cars and 'horse boxes' or lorries (UK) or 'floats' and trucks (AUS), humans and horses intermingle, sometimes but not always separated by flimsy tape. Humans and horses were in close contact and interaction around the site, and off on course on the endurance routes, and event organisers were aware of the risks inherent in these multispecies spaces, as this event organiser, a former endurance rider himself, explained:

We try and man [sic] every road crossing, the police know the ride's going ahead, the local council know the ride's going ahead, we have an emergency reference number if there is an incident on the ride that we can quote when we dial 999 . We had a lady fracture her spine last year and mountain rescue had to come and get her. She did, typically, she did it in an inaccessible part ... but we dealt with it and there were no real dramas over it, although it was particularly nasty, and she's actually coming back to ride this year. [Event organiser, UK, 17/06/18]

Although steps are taken to minimise risk, in a multispecies event involving large numbers of large animals (horses, in this case) in close contact with humans, the possibility for accidents is increased. Furthermore, horse riding is an inherently accident-prone sport (Paix, 1999). This can be further compounded through inexperience and misjudgements by horse handlers (Tabernaberri, 2006). Event participants, whether organisers, support volunteers or riders, are often experienced horse people themselves, and it is assumed they know these risks and are mentally prepared for dealing with them. However, some participants at multispecies events are not experienced in interactions with nonhuman animals, and may experience such risk and accidents in different ways. The first aider at the same event, an ex-paramedic, does not have personal horse experience, and remembered the same accident reported above as 'really stressful', as this fieldnote record reports: 
He always sees a few falls. Talks about the problem last year when a woman broke her neck in a fall out on the ride. He tells me this was really difficult. He wanted the whole ride stopping as there were still horses and riders coming past which was really dangerous and especially when the air ambulance was called in, but the decision was made for the ride to continue ... I asked how they managed the air ambulance around the horses and he said they were brilliant - parked a bit away and walked over, so the other horses weren't spooked. He has already scoped out where the air ambulance can land at the venue this year if necessary. [Fieldnote, UK event, 24/06/18].

The multispecies event site needs to be designed to minimise and manage risk as an important contributor to enjoyable and safe experiences, but must also take into account the welfare needs of both humans and horses. During fieldwork in the UK the weather was unusually hot and sunny, resulting in challenges in terms of keeping cool for both humans and horses, and so heat shaped the experience of all participants. Endurance events often involve an overnight stay and both humans and horses camp in the event field, humans in a tent or horsebox, and horses in a corral, kept in place by electric fencing, as this fieldnote record reports:

Quite a few people have gazebos and awnings on vehicles to provide some much needed shade. Most have set up seating areas outside ... horses are corralled close to horseboxes and trailers at various points around the site. Some are lucky enough to have some shade from trees, but many don't. [Fieldnote, UK event, $15 / 07 / 18]$ 
As the day progressed the heat intensified, causing issues for horses and humans. Endurance riding is, as the name suggests, a long distance event, and one key aspect of the competitive format is returning the horse's heart rate to a low level within a set time of returning from a ride, before presentation for checking by a vet. While this helps ensure horse welfare, and reduce metabolic stress on horses, on very hot days this caused additional pressures for the humans, struggling in the heat themselves, who had to try and cool down hot sweaty horses under full sun in the middle of a field (the 'crewing' area), as these fieldnote records report:

There is no shade at all in the crewing area and it's getting hotter. This doesn't help with cooling horses and it's very hot for crew members.

See lots of people trying to encourage horses to drink, but many don't seem to want to. It is very hot now - late 20 s [degrees]. Some people give the horse a watery feed to encourage more fluid intake.

One horse is put straight in a white mesh rug [encourages cooling] and washed down through this. The team check the heart rate - "it's too high at the moment" - the horse is not ready to present to the vet yet, and gets more water poured over. [Fieldnote, UK event, 15/07/18].

Both people and horses were hot and tired, but the requirements of the event to present the horse to the vet for a heart rate check within a specified time, and to ensure that heart rate has lowered below a given rate, meant that humans deferred their own exhaustion and discomfort and concentrated on the horse's cooling and welfare. Getz (2002) has pointed out that the weather can make or break an outdoor festival, and this may be even more the case in multispecies events where the comfort and experiences of humans and other animals have to be taken into account and can be dictated by the weather. Furthermore, at endurance riding events so-called 'completion rates' - indicating the percentage of horses that passed the final 
vet check with an acceptable heart rate - drops in adverse weather cisrcumstances (Barnes, Kingston, Beetson and Kuiper, 2010). Lack of shade and shelter at event sites like the ones in this study (really, just fields) means that all participants - human and nonhuman - are exposed to the weather and this can shape experiences for good and bad.

\section{Multispecies connections, camaraderie and meaning}

Events are social occasions of temporary nature, and leisure events, like the ones in our study, represent an important investment of time and other resources for participants, who choose to spend their precious free time at the event. Horse-related leisure can be understood as a way of life, as much as a leisure activity, as the requirements to care for another animal and to invest time, money, emotion and energy mean that for many horse people their whole lives are structured around their horse-related activities (Dashper, 2017). Events are often the pinnacle of this year-round commitment, and carry meaning and significance for human participants, who look forward to the event, planning their training with their horse and arranging other aspects of life to enable them to spend a few days immersed in the multispecies event. The following extracts from our fieldnotes illustrate the importance participants place on these events, and the opportunity they give for them to spend time with their horses:

Steve, 64, member of the ride committee. He explains how he enjoys the camaraderie with and the company of horses, the playing with horses. [Fieldnote, Australia event, 26/05/18] 
Sarah, rider. She says for her, horsemanship [sic] is very important. She enjoys spending time with her horse in nature. She loves pine trees and tall trees. [Fieldnote, Australia event, 26/05/18].

Liz, 63, rider. She explains how they [her and her horse] travelled up on Friday and camped over to make it all more enjoyable. She likes getting away with her... She shows me round her horsebox where she is sleeping. They could have travelled down this morning, but then they'd have to do $34 \mathrm{~km}$ in this heat. If they are doing $64 \mathrm{~km}+$ she always comes the night beforehand or she would be too tired. She used to stay in a B\&B when she came to these events but now sleeps in the horsebox - "it's nice to be with my horse". [Fieldnote, UK event, 07/07/18].

The opportunity to just spend time together with their horse is a key aspect of what makes these event experiences enjoyable and memorable. For Steve, and many other participants, there is a sense of 'being in it together' with his horse when out on an endurance ride, of relaxing together and having fun. Sarah expresses a commonly held sentiment, the enjoyment of experiencing nature and the bush/countryside together, while Liz explains how she actually forgoes her own comfort, which would probably be greater in a B\&B than camped in her horsebox, because she'd rather be with her horse. In turn, some horses will also actually seek out physical closeness to their handlers, and call out for them when separated, as we observed.

An experienced endurance rider at an event in Australia who has ridden many different horses at various events over the years explained how it is important to see each horse as unique and contributing to an individual partnership with the rider. Through this, each 
ride/event develops its own character, which is shaped by the individual personalities of both horse and rider, and the relationship that develops between them (Australian event, 12/05/18). For human participants at these multispecies events, it is the experience of being with and spending time with their horse that matters, and that makes these events worthwhile. These experiences are shaped by both horse and rider as active agents, and strongly influecned by the relationship between the two. This contributes to the creation of memorable and meaningful experiences.

Human participants often expressed real concern for the welfare and well-being of their horse at endurance events, and were willing to adapt their own activities and behaviours to try and make things better for their horse. This was particularly evident during post-ride activities. When returning from an endurance ride, all participants are likely to be hot and tired - human and horse. Whereas the human athlete may need to cool down, rest and recuperate, in a multispecies endurance event this has to wait until the horse has been adequately cared for, as this fieldnote illustrates:

She [rider] tells me that the horse must always come first - before she gets a cup of tea or anything the horse is sorted. Fed, watered, washed down. As she talks to me, she is washing down the horse's legs and she explains that she never used to be able to get near them [the horse was fearful of having his legs touched] but now she can pretty much do anything with the horse, and she attributes this largely to the bond they have developed through endurance. [Fieldnote, UK event, 24/06/18].

We regularly observed riders putting the needs of the horse before their own comfort, and many participants explained how their involvement with endurance events had helped them 
establish a closer and more meaningful relationship with their horse. One competitive endurance rider at a UK event explained that on challenging rides she would sometimes engage in the practice of 'tailing' - actually dismounting and running next to or even behind the horse to give the horse a break on steep terrain:

We have to work together. It's a partnership. So if we need to go up a steep hill I get off and run next to her, then at the top I get back on and say 'right, come on', and we're off. It's more supportive for the horse, and it's all about teamwork.

She explained that, for her, enduruance is

all about the bond, the bond between horse and rider ... there's something very magical about getting you and your horse over $160 \mathrm{~km}$ of challenging riding. Sometimes the horse looks at you and says 'what are you doing?' and you say 'trust me, we can do it.' And that is just awesome. [Competitive rider, UK event, 07/07/18]

Although the hose cannot know the purpose of the event, or care about completing the distance within given parameters as the rider does, the horse does have to trust the rider to traverse often challenging terrain. Interspecies trust develops over time and is based on relationships built and sustained through close interaction (Dashper, 2017; Gilbert, 2014). The event is the public manifestation of these relationships. The value of the event experience for the rider is thus expressed through the care and concern shown for another (the horse) and the quality of the relationship developed over time and through experiences together at multiple events.

Not all interspecies encounters at events are positive, and both human rider and horse are likely to be in a heightened sense of awareness and arousal at the event, due to the strangeness of the surroundings (for the horse) and the desire to perform well at the event (for 
the human). Consequently one or both may exhibit signs of stress and/or excitement, which can lead to difficult, even dangerous encounters, as this fieldnote illustrates:

He [male rider] explains about an event that used to have a shotgun start that was 'just crazy'. There were horses bucking and people coming off everywhere.

[Fieldnote, Australia event, 26/05/18].

Riders at these events are (hopefully) experienced horse people, as are most officials, volunteers and spectators, and so are aware of how horses react when excited or stressed and so may take steps to reduce the potential for this to cause problems for others, as this fieldnote illustrates:

The start area has several other horses and riders nearby, as well as crew and officials standing around to help as needed. There is a race rider waiting to set off on course. She says to her support crew "I'll go over here. I don't want him [horse] to run someone over if he gets silly!” [Fieldnote, UK ride, 15/07/18].

While we cannot ask the horses to explain their own experiences in the way that we can ask human event participants, informed observation and discussions with their riders is revealing of aspects of those equine experiences. It was clear to see that many horses became excited at the beginning of the event, and this was backed up by the reports of their riders who could sense this and reacted accordingly to try and minimise the potential for negative outcomes, often by trying to move the horse into a space away from other horses and people.

An important aspect of endurance riding is the vet check - when the horse's heartrate and soundness are checked. This is done at the beginning and end of rides, and at intervals during rides of longer distances. The vet check area was often quite busy, and the presence of 
numerous hot horses and lots of people often resulted in the horses displaying behaviour that indicated they were excited and/or stressed, as this fieldnote illustrates:

At the vet check area an Arab stallion is having his heart rate checked. He is very excited, neighing a lot and dancing around which makes it difficult for the vet to monitor his heartrate. When he does get a reading it is too high. The handler takes the horse away and has a set amount of time to calm the horse down, lower the heartrate and re-present to the vet. She walks the horse away from the crowd, speaking calmly to him. She allows him to graze a bit, while an assistant pours water on him to cool him down ... They re-present for the vet, the horse appears calmer. This time the heartrate has lowered enough and the horse passes the check. [Fieldnote, UK ride, 24/06/18].

As an event involving multiple species there is potential for poor practice to have welfare implications, and so riders need to educate themselves in terms of good horsecare and associated welfare issues, as well as proper riding and understanding the specifics of the event format. Due to the nature of this sport, many officials get to know horses and their riders and assess changes over time. This can sometimes place officials in uncomfortable positions, as this comment illustrates:

To my dismay many riders ignore my advice and continue to present with horses in poor condition in regard to muscle tone and/or general behaviour. It saddens me on a personal level because it would be easy to make smaller personal changes that would benefit the individual horse and improve its quality of life [Fieldnote, Australia event, $12 / 05 / 18]$

Another vet and rider sums up his experience: 
The most commonly observed displays of riding styles are often ineffective in their seat and overall reliance on bits and reins, with horses not being worked biomechanically correctly. In my opinion, the main cause for this on-going incorrect equitation is that many people do not want to challenge, educate or improve themselves. In other words, most people do not critically interrogate their own riding [Fieldnote, Australia event, 12/05/18].

When actively involving another species in our leisure events humans may thus have an additional responsibility to educate themselves and reflect critically on their own practice, and how that may affect the nonhuman participant. Jönsson (2012) argues that because horses cannot give informed consent to take part in equestrian events, in the way that human participants can, their human riders and trainers have an increased moral obligation to act ethically and to foreground the welfare and experiences of their equine partner. The extent to which human particpants in multispecies events recognise and take on this responsibility warrants futher investigation.

Events bring together humans and horses at varying stages of horsemanship and skill level, and also bring these teams in contact with each other. This opens a space for reflection and learning but also confrontation and conflict. On an international level, there are currently serious issues to do with horse welfare affecting endurance riding and events (Horsetalk, 2019). This is set in an over-arching discussion of what 'proper' horse management and riding might entail ( McGreevy \& McLean, 2010: Tellington-Jones, 2006), and indicates an additional level of complexity to multispecies events, not to mention a moral imperative to consider the experiences of nonhuman animals we involve in our leisure events and practices. 


\section{Discussion}

Event managers are becoming increasingly aware of the importance of designing events as experiences, attempting to excite, engage and delight participants to ensure satisfaction and repeat custom. Event experiences are both personal and social, and in this article we have shown the value of recognising how the involvement of nonhuman animals can shape event experiences, for good and for bad. When nonhuman animals are explicitly involved in events, as in the equestrian endurance events in our study, they actively shape and co-create event experiences alongside the human participants (whether they be riders, support crew, volunteers, officials or event organisers). The horses are not comparable to pieces of equipment, like bikes in a cycling event for example, as they have the capacity to act, to influence and affect humans and nonhumans around them. Like humans, horses are individuals with distinct likes and dislikes, personalities and behavioural responses (Dashper, 2017). The relationships between horses and their human partners (referring to both riders and support crew) are as unique as relationships between people, and in the heightened atmosphere of an event different facets of these relationships come to the fore and influence the unfolding of activities and the experiences of those involved. This raises important questions related to the ethics of involving other animals in our leisure events, when those animals cannot understand the context or the purpose of the event, and thus cannot give consent or exercise choice about their involvement. We recognise the importance and complexity of these issues, but suggest that although animals, such as horses, cannot give consent or verbally disagree with their involvement, they can express dissatisfaction. They will show their unwillingness or discomfort in various ways, such as through behavioural responses like kicking and bucking, with such horses that do not accept the competitive environment not making 'good' competition animals. This is not to say that competition 
horses always enjoy what they do, or that we should not reconsider questions of consent and the unequal power between rider and horse, but indicates some of the complexities of these issues.

Therefore, to understand the experiences of participants in equestrian events - even if we focus solely on the experiences of human event participants - requires paying attention to interspecies encounters and relationships. Whether the horse is tired or excited, too hot or annoyed by flies, scared of something in the environment or seemingly relaxed and settled, affects the ways in which he or she will behave, respond to the surroundings and interact with others, human and equine. In such ways, horses are co-creaters of event experiences, actively shaping and helping create those encounters, whether they be memorable or mundane.

Experiences are memorable because they mean something to the participants, and in the case of equestrian multispecies events much of that meaning, for the human participants at least, comes from the relationship they have with their horse and the chance to spend time together, indulging in an enjoyable leisure activity, in ways similar to those expressed by participants in dog agility and other related activities (Gillespie et al., 2002; Hultsman, 2012). Throughout our study we were repeatedly told how important it was for the people involved to spend time with their horse, and the value of being together in a different, often beautiful, countryside location. Experiencing these places and these activities together is what makes equestrian endurance events special for people, and the meanings attached to these experiences are derived in large part from the richness of the multispecies relationships around which they are based. These relationships go far beyond the event, and encompass all the routine care and training throughout the year, but the event is the culmination of this devotion, a time for human and horse to enjoy the fruits of their shared labour together. 
It is clear to see how a multispecies perspective can add to understanding of experiences at equestrian events like those in our study, where the active involvement of nonhuman animals is a core aspect of the event. To focus entirely on the human participants would be to miss the ways in which the horses help shape the event, and the meanings and practices associated with it. Throughout our research we tried to pay attention to the experiences of both humans and horses, and drew on our own established equestrian experience to interpret equine behaviour, but we are aware that our account focuses more on the human than the nonhuman aspects of these experiences. Future research would benefit from more interdisciplinary work, combining ethology alongside social science, to produce richer accounts of these multispecies experiences. If the design of satisfying and memorable experiences is one of the core goals of event managers, then in multispecies contexts those experiences need to be considered from a more-than-human perspective. In equestrian events, the experiences of human participants are profoundly shaped by those of the equine participants, and the interactions between the two. To satisfy the paying guests (humans), event managers need to ensure that the non-paying horses are comfortable and safe, as human experiences and equine ones are inextricably linked.

It is perhaps obvious that in an explicitly multispecies context, like equestrian events, a morethan-human perspective has value and offers additional insight on event experiences.

However, we suggest that such a perspective has application in other less obvious contexts as well. Even in events that do not involve nonhuman animals as active participants, nonhumans are still involved. Our focus in this paper has been on animals, whether human or nonhuman, but a posthumanist, more-than-human perspective also makes space for considering the importance of other objects and things in a given context. Those 'things' could include the 
weather at an outdoor festival, passes and lanyards at a conference, cheese at a destination, or even a pint of beer at a music event (see Ren, 2011). While these 'things' may seem unimportant at first, they add to the eventscape and have a role to play in shaping event experiences and a more-than-human perspective could enable researchers to think more carefully about the various ways in which all 'things' - whether people, other animals, or inanimate objects - interact and help co-create event experiences.

More-than-human frameworks decentre people, and make explicit attempts to consider humans as but one part in a complex, multispecies world. The dominance of anthropocentrism in event studies encourages researchers to focus solely on humans, and our actions, intentions, experiences and motivations, but this obscures many of the other influences on events. By decentring human experience, more-than-human perspectives open up possibilities for exploring and understanding the richness of event experiences that involve multiple actors and species.

\section{Conclusions}

In this paper we have introduced a more-than-human perspective as a valuable way of researching event experiences and taking into account the active roles of nonhumans in helping to shape and coproduce those experiences. Research on event experiences is growing, as researchers and event managers become more aware of the importance of ensuring participants have memorable and rewarding experiences, leading to increased satisfaction and repeat custom, which is essential for the success of events. There are multiple approaches to researching 'event experience' evident in the literature which offer different insights, but all of these approaches are strongly anthropocentric, focusing solely on human actions, 
interactions and perspectives and ignoring the role that nonhuman others can and do play in shaping event experiences. Through introducing a more-than-human approach to event studies we have illustrated the value of moving beyond anthropocentric focus on human perspectives alone and instead recognising the rich, varied and important roles that nonhumans play in shaping and co-creating memorable event experiences. 


\section{References}

Barnes, A., Kingston, J., Beetson, S. \& Kuiper, C. (2010) Endurance veterinarians detect physiologically compromised horses in a $160 \mathrm{~km}$ ride. Equine Veterniary Journal. 42, 6-11. doi 10.1111/j.2042-3306.2010.00225.

Bennett, A., \& Woodward, I. (2016). Festival spaces, identity, experience and belonging. In A. Bennett, J. Taylor \& I. Woodward (eds) The festivalization of culture. Abingdon: Routledge, 25-40.

Berridge, G. (2012). Designing event experiences. In S. Page and J. Connell (eds) The Routledge Handbook of Events, Abingdon: Routledge, 273-288.

Bladen, C., Kennell, J., Abson, E. \& Wilde, N. (2018). Events Management: an Introduction (2nd Edition). London: Routledge

Bouchet, P., Bodet, G., Bernache-Assollant, I., \& Kada, F. (2011). Segmenting sport spectators: Construction and preliminary validation of the Sporting Event Experience Search (SEES) scale. Sport Management Review, 14(1), 42-53.

Brown, G., Lee, King, K. \& Shipway, R. (2015). Eventscapes and the creation of event legacies. Annals of Leisure Research. 18(4), 510-527

Carmago, P. (2007). Using tourist resources as tools for teaching and creating awareness of heritage in a local community. In Richards, G. (ed.) Cultural Tourism. New York: Howarth Press, 239-256.

Chang, T. Y., \& Horng, S. C. (2010). Conceptualizing and measuring experience quality: the customer's perspective. The Service Industries Journal, 30(14), 2401-2419.

Clarke, C., \& Knights, D. (2018). Who's a good boy then? Anthropocentric masculinities in veterinary practice. Gender, Work \& Organization: doi.org/10.1111/gwao.12244. 
Coghlan, A., \& Filo, K. (2013). Using constant comparison method and qualitative data to understand participants' experiences at the nexus of tourism, sport and charity events. Tourism Management, 35, 122-131.

Dashper, K. (2017). Human-animal relationships in equestrian sport and leisure. Abingdon: Routledge.

Dashper, K. \& Brymer, E. (2019). An ecological-phenomenological perspective on multispecies leisure and the horse-human relationship in events. Leisure Studies:. DOI: 10.1080/02614367.2019.1586981.

Funk, D. C. (2017). Introducing a Sport Experience Design (SX) framework for sport consumer behaviour research. Sport Management Review, 20(2), 145-158.

Getz, D. (2002). Why festivals fail. Event management, 7(4), 209-219.

Gilbert, M. (2014). Trust in interspecies sport. Sociology of Sport Journal, 31(4), 475-491. Gillespie, D. L., Leffler, A., \& Lerner, E. (2002). If it weren 't for my hobby, I'd have a life: dog sports, serious leisure, and boundary negotiations. Leisure Studies, 21(3-4), 285-304. Haraway, D. J. (2013). When species meet. University of Minnesota Press. Helgadóttir, G., \& Dashper, K. (2016) Dear international guests and friends of the Icelandic horse: Experience, meaning and belonging at a niche sporting event. Scandinavian Journal of Hospitality and Tourism, 16(4), 422-441.

Hickey, S., McIlwraith, F., Bruno, R., Matthews, A., \& Alati, R. (2012). Drug detection dogs in Australia: More bark than bite? Drug and Alcohol Review, 31(6), 778-783.

Holloway, I., Brown, L., \& Shipway, R. (2010). Meaning not measurement: Using ethnography to bring a deeper understanding to the participant experience of festivals and events. International Journal of Event and Festival Management, 1(1), 74-85. Horsetalk (2019). Proposed Endurance reforms tackle cheating, reward good horsemanship. April 17. Available from: https://www.horsetalk.co.nz/2019/04/17/endurance-reforms- 
cheating-

horsemanship/?fbclid=IwAR3ZndxQeTRHoaDHDCCV2zffz6dBGC9rH2BGzYtvA9myK4g s87SvARZywwk [Accessed 23/04/19].

Hultsman, W. Z. (2012). Couple involvement in serious leisure: Examining participation in dog agility. Leisure Studies, 31(2), 231-253.

Hurlburt, R. T., \& Heavey, C. L. (2001). Telling what we know: describing inner experience. Trends in Cognitive Sciences, 5(9), 400-403.

Jaimangal-Jones, D. (2014). Utilising ethnography and participant observation in festival and event research. International Journal of Event and Festival Management, 5(1), 39-55.

Jönsson, K. (2012). Humans, horses, and hybrids: On rights, welfare, and masculinity in equestrian sports. Scandinavian Sport Studies Forum; (3), 49-69.

Kirksey, S. E., \& Helmreich, S. (2010). The emergence of multispecies ethnography. Cultural Anthropology, 25(4), 545-576.

Kruger, M., \& Saayman, M. (2012). Creating a memorable spectator experience at the Two Oceans Marathon. Journal of Sport \& Tourism, 17(1), 63-77.

Lloro-Bidart, T. (2017). A feminist posthumanist political ecology of education for theorizing human-animal relations/relationships. Environmental Education Research, 23(1), 111-130.

Madden, R. (2014). Animals and the limits of ethnography. Anthrozoös, 27(2), 279-293. Madrigal, R. (2003). Investigating an evolving leisure experience: Antecedents and consequences of spectator affect during a live sporting event. Journal of Leisure Research, 35(1), 23-48.

Maklan, S., \& Klaus, P. (2011). Customer experience: are we measuring the right things? International Journal of Market Research, 53(6), 771-772.

McLean, A. \& McLean, M. (2008). Academic Horse Training. Clonbinane: AEBC. McGreevy, P. \& McLean, A. (2010). Equitation Science. Chichester: Wiley-Blackwell. 
Morgan, M. (2006). Making space for experiences. Journal of Retail \& Leisure Property, 5(4), 305-313.

Morgan, M. (2008). What makes a good festival? Understanding the event experience. Event Management, 12(2), 81-93.

Nevzorov, A. (2011). The Horse Crucified and Risen. Charleston: Nevzorov Haute Ecole.

Ogden, L. A., Hall, B., \& Tanita, K. (2013). Animals, plants, people, and things: A review of multispecies ethnography. Environment and Society, 4(1), 5-24.

Paix, B.R. (1999) Rider injury rates and emergency medical services at equestrian events. British Journal of Sports Medicine. 33(1): 46-48.

Pacini-Ketchabaw, V., Taylor, A., \& Blaise, M. (2016). Decentring the human in multispecies ethnographies. In C. Taylor and C. Hughes (eds) Posthuman research practices in education. Palgrave Macmillan, London, 149-167.

Pettersson, R., \& Getz, D. (2009). Event experiences in time and space: A study of visitors to the 2007 World Alpine Ski Championships in Åre, Sweden. Scandinavian Journal of Hospitality and Tourism, 9(2-3), 308-326.

Pine, B. J., \& Gilmore, J. H. (1998). Welcome to the experience economy. Harvard Business Review, 76, 97-105.

Pine, B. J., \& Gilmore, J. H. (2000). Satisfaction, sacrifice, surprise: three small steps create one giant leap into the experience economy. Strategy \& Leadership, 28(1), 18-23. Podhajsky, A. (1970). My Horses, My Teachers. London: Harrap.

Ren, C. (2011). Non-human agency, radical ontology and tourism realities. Annals of Tourism Research, 38(3), 858-881.

Smith, A.V., Proops, L., Grounds, K. Wathan, J. and McComb, K. (2016). Functionally relevant responses to human facial expressions of emotion in the domestic horse (Equus caballus). Biology Letters, 1 February: doi.org/10.1098/rsbl.2015.0907 
Stone, E. (2019). What's in it for the cats? Cat shows as serious leisure from a multispecies perspective. Leisure Studies. doi.org/10.1080/02614367.2019.1572776.

Tattersall, J. and Cooper, R. (2014) Creating the Eventscape. In Sharples, L, Crowther, P., May, D. and Orefice, C. (eds) Strategic Event Creation. Oxford: Goodfellows, 141-165.

Tabernaberri, C. (2006). Through the Eyes of the Horse. Melbourne: Moonrise Media.

Tellington-Jones, L. (2006). The Ultimate Horse Behaviour and Training Book. Vermont: Trafalgar Square.

Wood, E.H. (2015). How we think we felt: The importance of recollected experience and how to capture it. In: The Festival and Event Experience. Leisure Studies Association, 127 151.

Wood, E. H., \& Kenyon, A. J. (2018). Remembering together: the importance of shared emotional memory in event experiences. Event Management, 22(2), 163-181.

Wood, E. H., \& Masterman, G. (2008, January). Event marketing: Measuring an experience. In 7th International Marketing Trends Congress, Venice.

Wood, E. H., \& Moss, J. (2015). Capturing emotions: experience sampling at live music events. Arts and the Market, 5(1), 45-72.

Ziakas, V., \& Costa, C.A. (2010). 'Between theatre and sport' in a rural event: Evolving unity and community development from the inside-out. Journal of Sport and Tourism, 15(1), 7-26. 